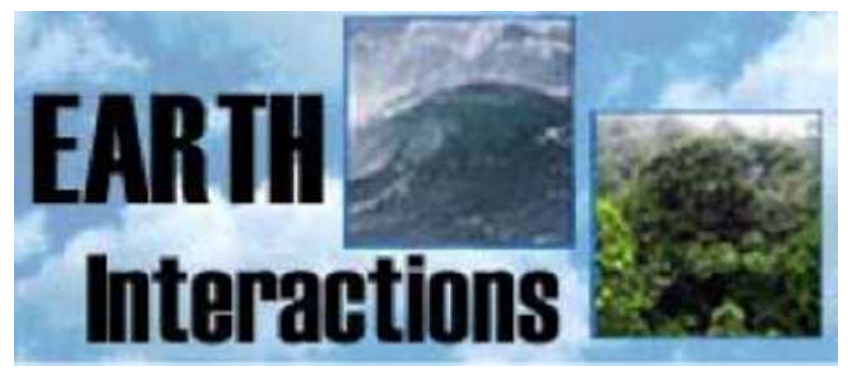

Copyright $($ C) 2005, Paper 09-009; 7,505 words, 11 Figures, 0 Animations, 2 Tables. http://EarthInteractions.org

\title{
Validation of MODIS Active Fire Detection Products Derived from Two Algorithms
}

\section{Jeffrey T. Morisette*}

Terrestrial Information Systems Branch, NASA Goddard Space Flight Center, Greenbelt, Maryland

\section{Louis Giglio and Ivan Csiszar}

Department of Geography, University of Maryland, College Park, College Park, Maryland

\section{Alberto Setzer}

Centro de Previsão do Tempo e Estudos Climáticos, INPE, Sao Jose dos Campos, Sao Paolo, Brazil

\section{Wilfrid Schroeder, Douglas Morton, and Christopher O. Justice}

Department of Geography, University of Maryland, College Park, Maryland

Received 16 September 2004; accepted 29 December 2004

ABSTRACT: Fire influences global change and tropical ecosystems through its connection to land-cover dynamics, atmospheric composition, and the global carbon cycle. As such, the climate change community, the Brazilian government, and the Large-Scale Biosphere-Atmosphere (LBA) Experiment in

* Corresponding author address: Jeffrey T. Morisette, Terrestrial Information Systems Branch, NASA Goddard Space Flight Center, Mail Code 614.5, Greenbelt, MD 20771.

E-mail address: jeff.morisette@nasa.gov 
Earth Interactions - Volume 9 (2005) - Paper No. 9 - Page 2

Amazonia are interested in the use of satellites to monitor and quantify fire occurrence throughout Brazil. Because multiple satellites and algorithms are being utilized, it is important to quantify the accuracy of the derived products. In this paper the characteristics of two fire detection algorithms are evaluated, both of which are applied to Terra's Moderate Resolution Imagine Spectroradiometer (MODIS) data and with both operationally producing publicly available fire locations. The two algorithms are NASA's operational Earth Observing System (EOS) MODIS fire detection product and Brazil's Instituto Nacional de Pesquisas Espaciais (INPE) algorithm. Both algorithms are compared to fire maps that are derived independently from 30-m spatial resolution Advanced Spaceborne Thermal Emission and Reflection Radiometer (ASTER) imagery. A quantitative comparison is accomplished through logistic regression and error matrices. Results show that the likelihood of MODIS fire detection, for either algorithm, is a function of both the number of ASTER fire pixels within the MODIS pixel as well as the contiguity of those pixels. Both algorithms have similar omission errors and each has a fairly high likelihood of detecting relatively small fires, as observed in the ASTER data. However, INPE's commission error is roughly 3 times more than that of the EOS algorithm.

KEYWORDS: Fire monitoring, MODIS, Validation, Satellite fire detection

\section{Backgound}

Fire monitoring continues as an area of interest within global change research on ecosystem dynamics through its connection to land cover and change, atmospheric composition, and the global carbon cycle (USCCSP 2004). The influence of fire in tropical ecology has been established (Goldammer 1990) and fire has been associated with land-cover dynamics (Elvidge et al. 2001; Eva and Lambin 2000) as well as with carbon cycling (Potter et al. 2001). This implies the importance of fire statistics to the Large-Scale Biosphere-Atmosphere (LBA) Experiment in Amazonia. Polar-orbiting satellite systems have been extensively used to monitor the global distribution of fire (Dwyer et al. 2000; Malingreau and Gregoire 1996; Justice and Dowty 1994). Regional fire monitoring in Brazil has been done with Defense Meteorological Satellite Program (DMSP) Operational Linescan System (OLS) (Elvidge et al. 2001), Advanced Very High Resolution Radiometer (AVHRR) (Setzer and Pereira 1991a; Franca and Setzer 2001), Moderate Resolution Imaging Spectroradiometer (MODIS), and Geostationary Operational Environmental Satellite (GOES) (Setzer et al. 1994; Prins et al. 1998).

This work is part of LBA that is carried out specifically under Land Cover and Land Use Change Investigation 23 (LC-23): quantifying the accuracy of MODIS fire products and establishing their relationship with land-cover dynamics. The LC-23 project is working to provide accuracy information on satellite-derived fire products to other fire-related LBA projects, including, but not limited to,

- Trace Gas and Aerosol Fluxes Project 3: Characterization of aerosol optical properties and solar flux for NASA's LBA-Ecology program (LBA-ECO);

- Trace Gas and Aerosol Fluxes Project 10: Tropical biomass fires and tropospheric chemistry: chemistry and production of smoke in Brazil; 
Earth Interactions - Volume 9 (2005) - Paper No. 9 • Page 3

- Land Cover and Land Use Change Project 2: Land-cover/land-use change and carbon dynamics in an expanding frontier in western Amazonia: Acre, Brazil; and

- Carbon Dynamics Project 5: Amazon scenarios: modeling interactions among land use, fire, and climate.

This research and analysis builds on the MODIS land team's validation strategy to derive MODIS-like products from high-resolution imagery and compare these to MODIS products (Morisette et al. 2002). The research is integrated with the Global Observation of Forest Cover (GOFC)/Global Observation of Land Dynamics (GOLD) program and the Committee on Earth Observing Satellites (CEOS) global validation activities. These international entities have helped define the role of regional partners in validating global fire products (see information online at http://gofc-fire.umd.edu). Integration with GOFC/GOLD and CEOS maximizes the applicability of this research beyond Brazil to the international effort to better understand global fire product accuracy.

The primary goal of this paper is to evaluate the characteristics of two fire detection algorithms, both of which are applied to Terra's MODIS data and with both operationally producing publicly available fire locations. We start by describing the two Terra MODIS fire detection algorithms - one produced as the National Aeronautics and Space Administration's (NASA's) operational, archived, Earth Observing System (EOS) MODIS fire detection product (henceforth referred to as the EOS algorithm), and the other produced by Brazil's Instituto Nacional de Pesquisas Espaciais (INPE; National Institute for Space Research). We then describe the binary fire detection algorithm applied to the Advanced Spaceborne Thermal Emission and Reflection Radiometer (ASTER) imagery and how the resulting binary fire imagery derived from ASTER, which has $30 \mathrm{~m} \times 30 \mathrm{~m}$ spatial resolution, is summarized for comparison with each individual MODIS 1-km pixel. This paper builds upon the previous work of coupled ASTER and EOS MODIS fire detection in southern Africa (Morisette et al. 2005). The corresponding MODIS and summarized ASTER data provide detailed information with which to evaluate the two MODIS fire detection products. A quantitative comparison is accomplished through logistic regression and the application of accuracy assessment curves (Morisette and Khorram 2000) applied to ASTER versus MODIS error matrices. We use the analysis to empirically quantify the detection envelope for the INPE and EOS algorithms with respect to fire size and spatial continuity as estimated by the ASTER fire maps. This paper goes beyond previous MODIS fire validation work that has been done for southern Africa (Morisette et al. 2005) by considering the INPE fire detection algorithm, focusing on a new region, developing a more refined ASTER fire detection algorithm, and putting the ASTER/MODIS statistical analysis in the context of the more familiar error matrix.

\section{Fire monitoring history in Brazil}

In the context of strengthening the structure of law enforcement, prevention, and control of environmental-related activities, the Instituto Brasileiro do Meio Am- 
biente e dos Recursos Naturais Renováveis (IBAMA; the Brazilian Institute for the Environment and Natural Renewable Resources) was created in 1989 under the jurisdiction of the Ministry of the Environment. Among the diverse areas under the responsibility of this agency, the activities of fire monitoring, prevention, and suppression received special attention. In 1991 the Sistema Nacional de Prevenção e Controle aos Incêndios Florestais (PREVFOGO; National Fire Prevention and Control System) was created within IBAMA and started to use-in a semioperational way-satellite fire detection information coming from National Oceanic and Atmospheric Administration (NOAA) AVHRR data generated by INPE. In 1985 the first fire detections with AVHRR were made as part of the NASA-INPE Atmospheric Boundary Layer Experiment (ABLE)-2A mission, resulting in the report of previously unknown biomass burning in the Amazon, with regional transport of emissions (Andreae et al. 1988). In 1987 the first operational monitoring project started, supplying regional offices of the Brazilian Forest Institute (which later became IBAMA) with coordinates of fires sent by Telex machines. The results showed an unknown scale of biomass burning associated with massive deforestation in the Amazon, awakening the scientific community to the global environmental effects of such practices (Setzer and Pereira 1991a; Setzer and Pereira 1991b). The monitoring system continued to improve and the user base expanded. Extensive field experience was gained during many years in the combat and control of vegetation fires and in validating the satellite-derived product (Setzer et al. 1994).

March 1998 was a decisive period in fire monitoring. Roughly $12000 \mathrm{~km}^{2}$ of forests burned in the northern state of Roraima. The Brazilian government established and funded a bilateral effort between INPE and IBAMA, where the former was responsible for improving the detection and monitoring of fires using satellite imagery and the latter was to implement policies of fire management and combat in critical areas of the Amazon region. Innovations in computer technology and in geoprocessing, and the creation and widespread use of the Internet, fostered the development of a large number of products. Three Brazilian Web pages should be explored in detail to understand the results and magnitude of this effort (see information online at http://www.cptec.inpe.br/queimadas, http://www.dpi.inpe. br/proarco/bdqueimadas, and http://www2.ibama.gov.br/proarco). Products include IBAMA daily reports of fires in conservation units in the country, Indian territories, and in forested areas in the Amazon; comparative tables of fire occurrences; a geographical information system (GIS) and database of fire detection for use on the Internet by the general public; fire risk maps of analysis and forecasts; etc. Dozens of institutional and hundreds of individual users access this fire system, which in the last years has been also expanded to Bolivia, Paraguay, Peru, and Venezuela. The IBAMA departments that are involved in fire management and control, PREVFOGO and the Programa de Prevenção e Controle de Queimadas e Incêndios Florestais na Amazônia Legal (PROARCO), direct the operational work related to fire on a national basis. Firemen and state environmental agencies and forestry institutes, as well as the civil defense and the army (in extreme events), engage in actual fire combat.

The PROARCO monitoring system uses a set of satellite sensors to monitor fires, fire risk, and meteorological conditions in all of the Amazon area and some neighboring countries (Pereira et al. 1999). To track fire dynamics in the Amazon, 
Earth Interactions - Volume 9 (2005) - Paper No. 9 • Page 5

the need for a more reliable, fast-response hot-spot detection system required a new approach from PROARCO shortly after its implementation. Working toward the improvement of the information being generated, by mid-2000 PROARCO started a new phase that would lead its fire monitoring system to a much more sophisticated level. At that time operational fire monitoring, using both the AVHRR (Setzer and Pereira 1991a) and GOES (Molenar et al. 1996; http://hadar. cira.colostate.edu/ramsdis/online/BRZFIRE.html) data, was in place. Throughout operational use at IBAMA, AVHRR and GOES fire data have proven to be a valuable tool, adding an improved detection capability for the whole forest fire detection system. Even though the fire detection system was showing clear signs of improvement, some uncertainties or eventual mismatches between AVHRR and GOES fire data showed that there were still some gaps. To help reduce these gaps IBAMA gained access to the MODIS fire data, a new-generation satellite sensor carrying some spectral bands specifically designed for fire detection (Justice et al. 2002). Considering its relatively early stage of implementation, MODIS fire data had to be validated before it could be fully incorporated in the operational routine of fire monitoring at IBAMA. Currently two algorithms are applied to the MODIS data stream-one developed by the NASA Earth Observing System program developed at the University of Maryland (Justice et al. 2002), the other by INPE (described below). Understanding the accuracy associated with the fire detections from MODIS helps IBAMA understand how to best integrate the MODIS detections with data from other sensors and algorithms.

\section{Data: Satellite fire detection algorithms}

MODIS (Kaufman et al. 1998) is a 36-band instrument with substantially improved capabilities for fire mapping as compared to the AVHRR. The first MODIS sensor is on board the Terra satellite, which was launched in December 1999 and has a daytime local overpass of about 10:30 A.M. The second MODIS sensor is on board the Aqua satellite, launched in May 2002, with a 1:30 P.M. daytime local overpass. One of the land products derived from the MODIS sensor is a pixel resolution fire mask, separated into files representing $5 \mathrm{~min}$ of image acquisition along a given swath (Justice et al. 2002). The increased saturation temperatures of the 1-km-resolution 3.9- and 11- $\mu \mathrm{m}$ sensors decrease the ambiguities leading to false alarms or omission errors typical of the AVHRR-based fire products (Giglio et al. 2003).

\subsection{MODIS INPE}

Starting mid-2002, daily processing of MODIS direct broadcast data began at INPE. INPE's satellite receiving station located in Cuiabá, Mato Grosso, in central Brazil receives Terra and Aqua imagery and disseminates that information to the Centro de Previsão de Tempo e Estudos Climáticos (CPTEC; Center for Weather Forecast and Climate Studies) in Cachoeira Paulista, São Paulo, where fire products are designed and implemented. The MODIS INPE algorithm relies on the well-consolidated methodology of fixed threshold algorithms (Setzer and Pereira 1991a; Setzer et al. 1994; Setzer and Malingreau 1996; Li et al. 2001). INPE has successfully used this method with the NOAA AVHRR series of satellite data 
Earth Interactions • Volume 9 (2005) • Paper No. 9 • Page 6

for nearly two decades. The daytime algorithm uses empirically derived thresholds. Pixels are classified as "fire" if two conditions are satisfied: band $20>3000$ digital numbers (DNs) and band $9<3300$ DNs. The band 20 test is used to determine pixels that are potentially associated with vegetation fires at the surface while the band 9 test is used to eliminate eventual sources of contamination that affect the fire product (e.g., bright targets). The nighttime algorithm requires one condition, band $20>3000$. Text files with fire coordinates are disseminated to regional fire monitoring centers (e.g., PROARCO) and made available to the user community under a Web-based GIS system within approximately $2 \mathrm{~h}$ after the satellite overpass time (information online at http://tucupi.cptec.inpe.br/ queimadas/index_modis.html).

\subsection{MODIS EOS}

Fire detection within the EOS MODIS fire products is performed using a contextual algorithm that exploits the strong emission of midinfrared radiation from fires (Dozier 1981; Matson and Dozier 1981). Briefly, multiple tests are applied to each pixel of the MODIS swath that look for the characteristic signature of an active fire in which the 4- $\mu \mathrm{m}$ brightness temperature, as well as the 4- and $11-\mu \mathrm{m}$ brightness temperature difference, departs substantially from that of the nonfire background. Relative thresholds are adjusted based on the natural variability of the scene. Additional specialized tests are used to eliminate false detections caused by sun glint, desert boundaries, and errors in the water mask. The algorithm ultimately assigns to each pixel one of the following classes: missing data, cloud, water, nonfire, fire, or unknown. A detailed description of the detection algorithm is provided by Giglio et al. (Giglio et al. 2003).

In this study we used the "Collection 4" level 2 (swath based) fire product, available from the Land Processes Distributed Active Archive Center (DAAC) via the EOS Data Gateway (http://edcimswww.cr.usgs.gov/pub/imswelcome/).

\subsection{ASTER}

ASTER (Yamaguchi et al. 1998), also on board the Terra satellite, provides near-nadir view measurements in four visible and near-infrared bands between 0.52 and $0.86 \mu \mathrm{m}$, six shortwave infrared (SWIR) bands between 1.6 and $2.43 \mu \mathrm{m}$, and five thermal infrared (TIR) bands between 8.125 and $11.65 \mu \mathrm{m}$ at 15-, 30-, and 90-m resolutions, respectively. The coincident high-resolution, multispectral measurements within a $\sim 60 \mathrm{~km}$ swath near the center of the MODIS swath provide a unique opportunity to analyze the finescale features within the MODIS pixels, such as active fires.

In this study we utilized 22 ASTER Level 1B-calibrated radiance scenes obtained through the NASA Earth Observing System Data Gateway (EDG). Both the MODIS and ASTER data are available through EDG (online at http://edcimswww. cr.usgs.gov/pub/imswelcome/); the file name in the table provides the unique identifier for each image dataset for the Terra MODIS Thermal Anomalies/Fire 5-min Level 2 1-km swath (MOD14), the Terra MODIS Level 1A Geolocation data (MOD03; required input for proper geolocation of MOD14 swath data), and 
the ASTER Level 1B data. All of these data can be found in the EOS data gateway by searching for this file name as the "local granule ID." Figure 1 shows the distribution of these scenes in space and Table 1 provides details for the acquisition date, center latitude and longitude, cloud cover, and file name for each ASTER scene and the associated MODIS file names.
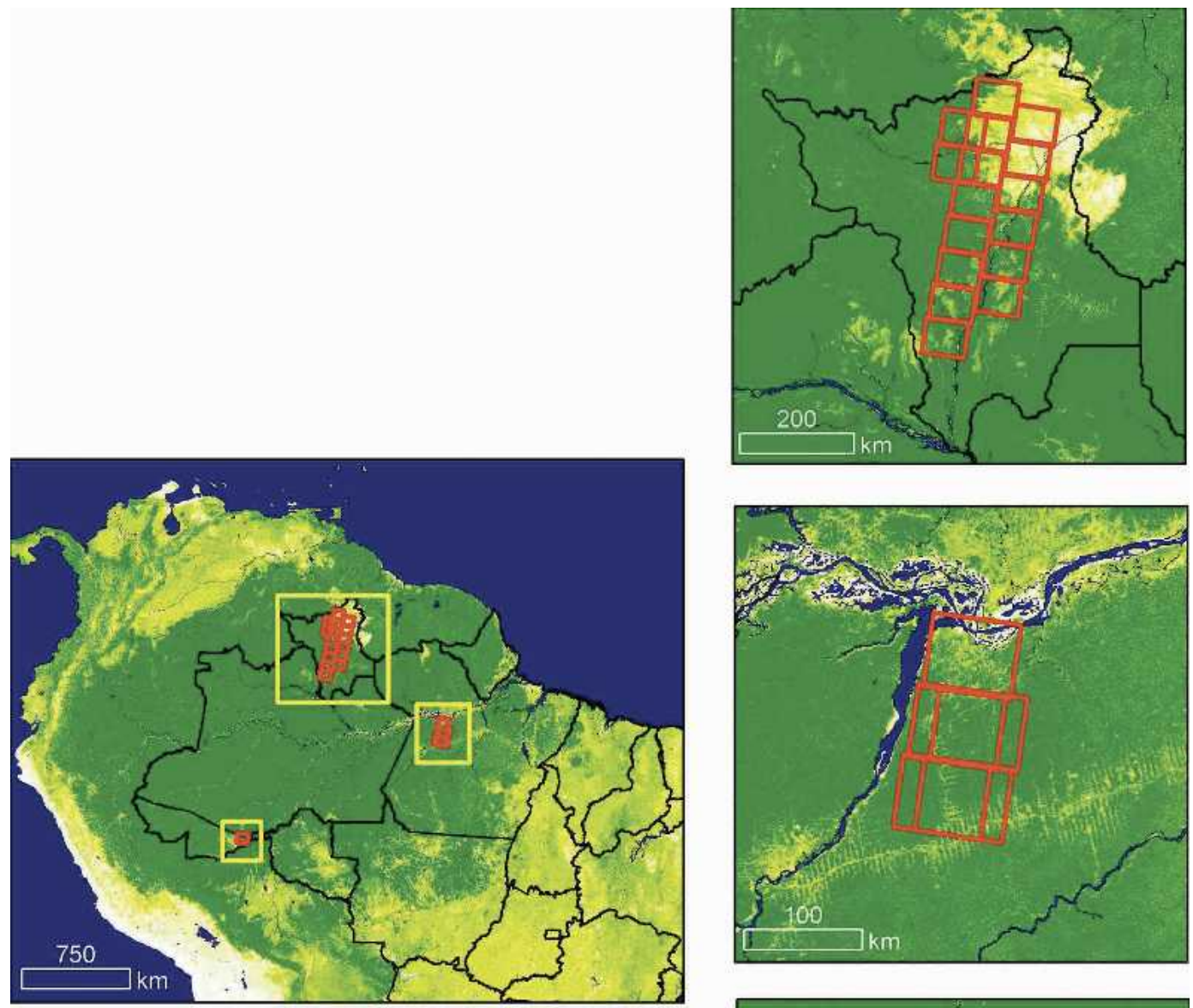

\section{Legend}

\section{ASTER Scene Boundaries}

$\square$ Brazil State Boundaries

0

2001 MODIS VCF

Percent Tree Cover

100
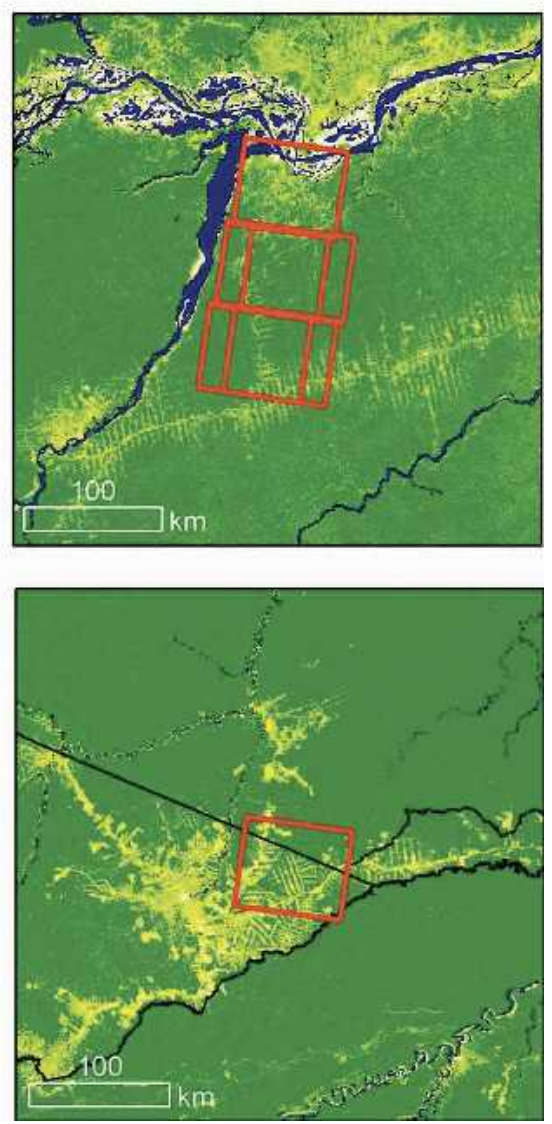

Figure 1. Location map for the 22 ASTER scenes used in this study. 
Earth Interactions - Volume 9 (2005) • Paper No. 9 • Page 8

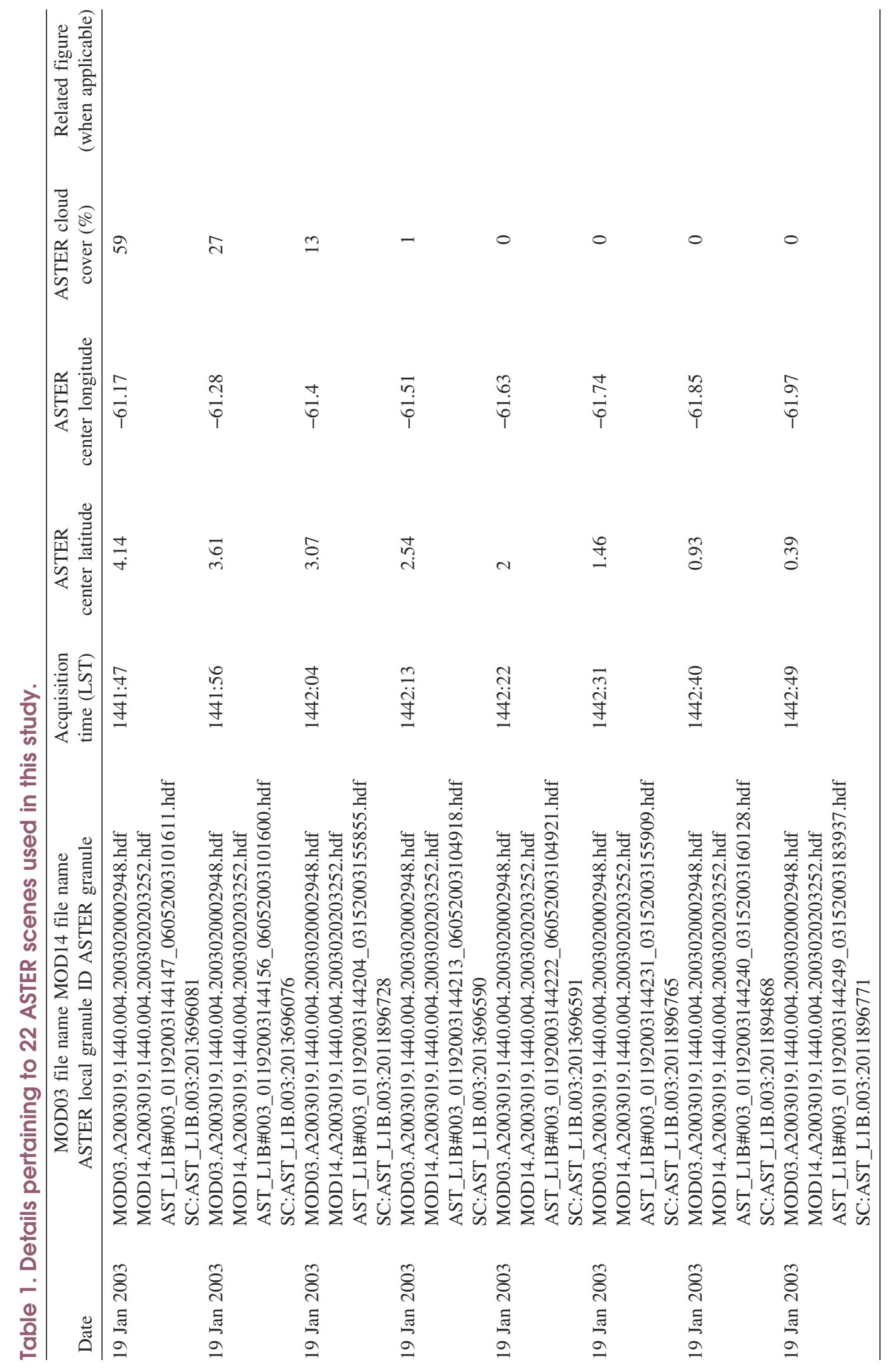


Earth Interactions - Volume 9 (2005) - Paper No. 9 • Page 9

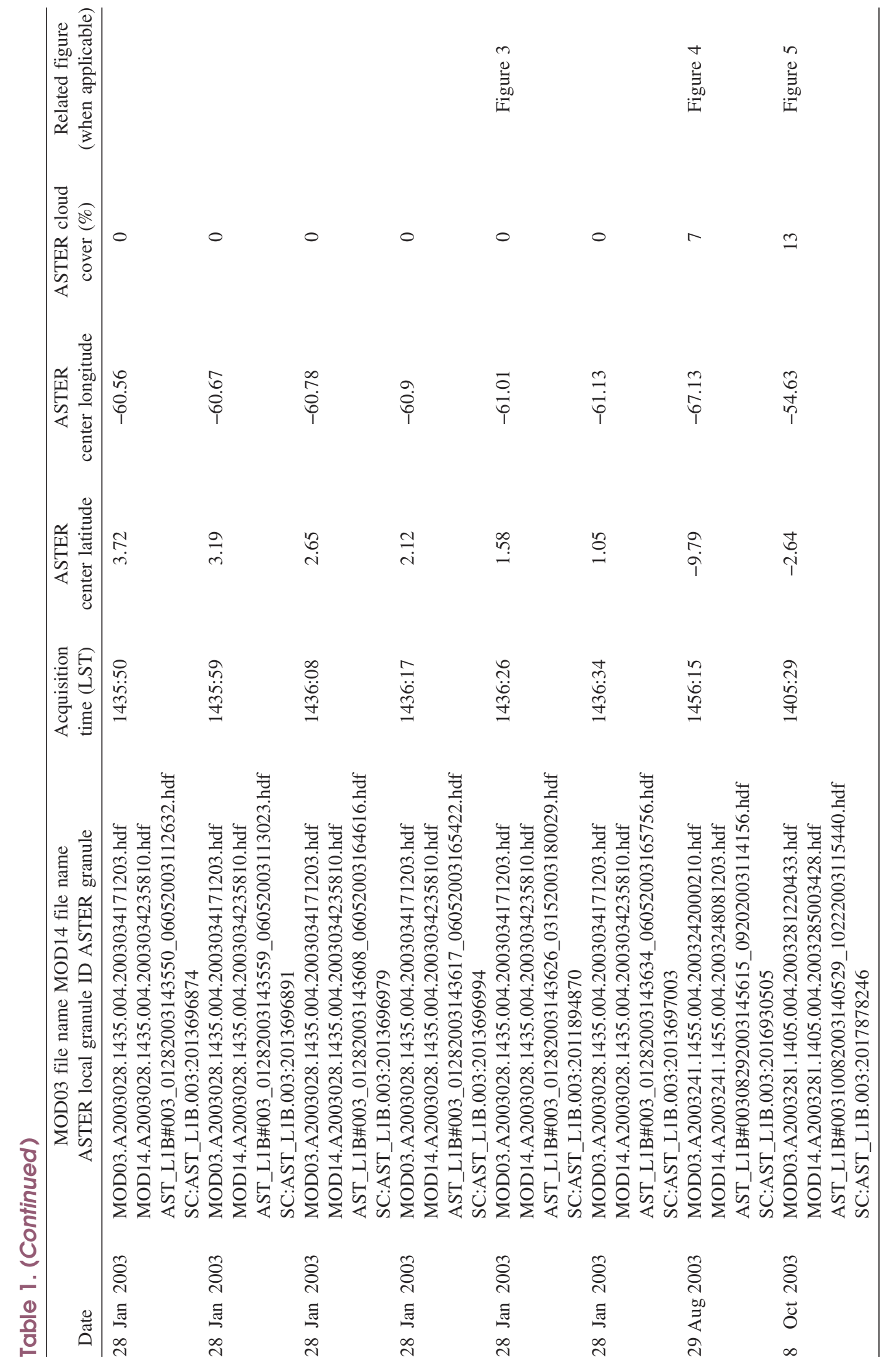




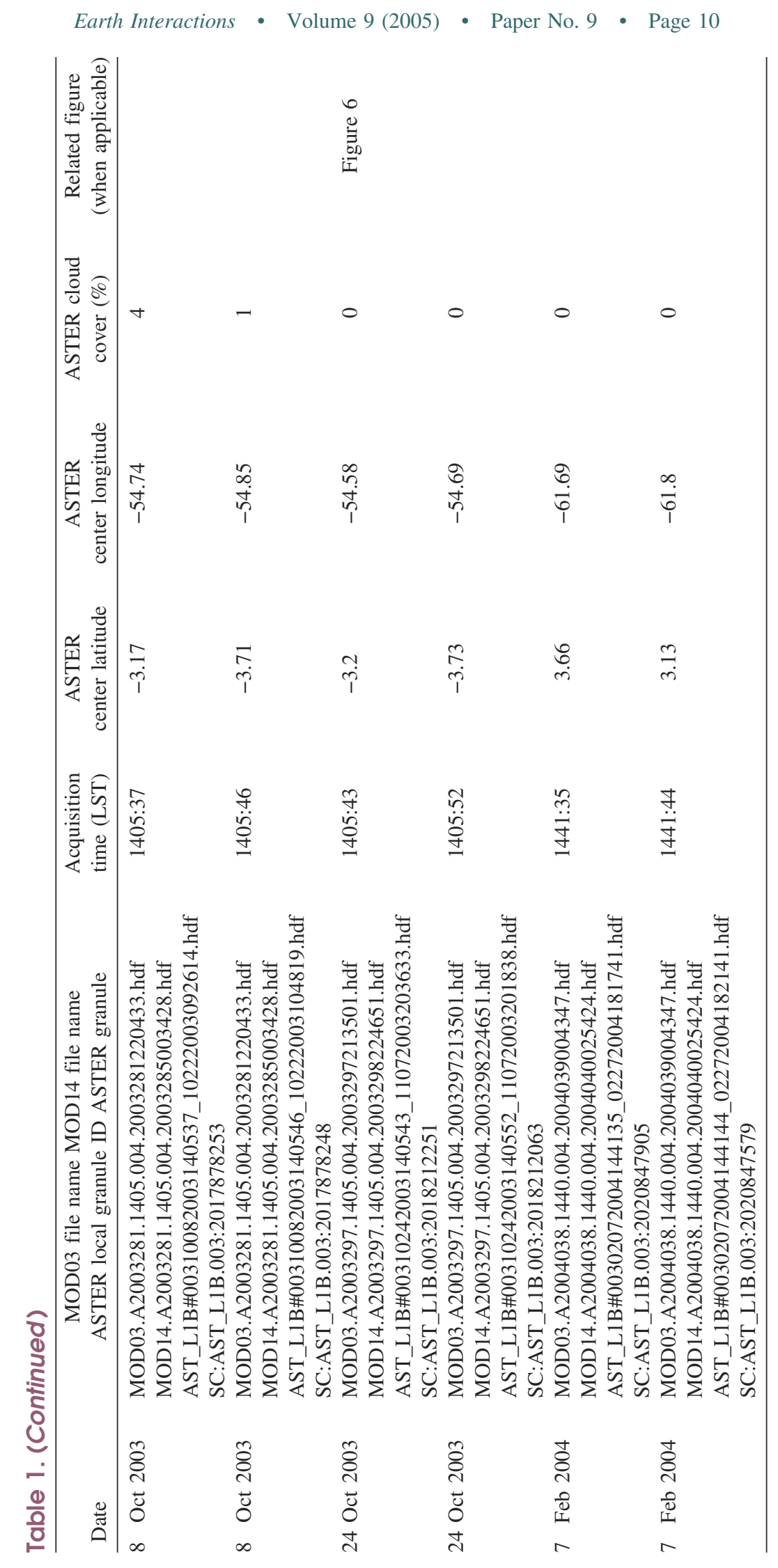


Earth Interactions • Volume 9 (2005) • Paper No. 9 • Page 11

\section{Methods}

\subsection{ASTER fire map}

ASTER Level 1B-calibrated radiances were first converted to top-of-atmosphere reflectances. We then used ASTER band $3 \mathrm{~N}$ (band $3=0.76-0.86 \mu \mathrm{m}, \mathrm{N}=$ nadir view) and $8(2.295-2.365 \mu \mathrm{m})$ reflectance images to prepare individual fire masks. These bands exhibit a high correlation in typical terrestrial scenes but have vastly different responses to the blackbody radiation emitted by fires: the presence of a fire within an ASTER pixel significantly increases the band 8 reflectance relative to the reflectance observed in band $3 \mathrm{~N}$. ASTER band 3 data are originally available at $15-\mathrm{m}$ spatial resolution; while band 8 data are available at $30-\mathrm{m}$ spatial resolution. To compare it to band 8 data on a pixel-by-pixel basis, we degrade the band 3 data to 30-m spatial resolution through a simple averaging. ASTER pixels containing actively burning fires were identified by considering both the ratio and difference of band 8 and band $3 \mathrm{~N}$, where large ratios and large differences indicate fires. A pixel for which the ratio is greater than 2 and the difference is greater than 0.2 is considered to be an "obvious" fire and is flagged as an active fire. A pixel for which the ratio is between 1 and 2 and the difference is between 0.1 and 0.2 is compared to the difference and ratio for surrounding pixels. The mean and standard deviation of both the ratios and differences for a $61 \times 61$ pixel square neighborhood centered on each pixel are calculated. Pixels flagged as obvious fires are excluded in calculation of the mean and standard deviation. When a pixel's ratio is more than either (a) three standard deviations or (b) 0.5 beyond the mean ratio and the pixel's difference is either (a) three standard deviations or (b) 0.05 beyond the mean difference, that pixel is flagged as an active fire. (For global application, additional false alarm rejection tests are probably required, but the lack of sun glint and other problematic features in the ASTER scenes used in this study rendered such tests unnecessary.) Manual inspection of each ASTER scene was performed to ensure that the resulting fire masks missed no visually apparent fires and contained no false fire pixels.

\subsection{ASTER summaries}

Within a given MODIS pixel there are many ways to summarize the corresponding ASTER fire map. We were most interested in summaries related to the spatial extent and distribution of fires. To quantify the spatial extent of fires, we summed the number of ASTER fire pixels within each MODIS pixel [we used the geolocation information from MODIS to select the ASTER pixels to aggregate for each MODIS pixel, following Morisette et al. (Morisette et al. 2005)]. To summarize the spatial distribution of the fires we calculated the mean size of contiguous fires within each MODIS pixel. Contiguous fires were defined as fire pixels that shared a side or diagonal connection, and each connected group of fire pixels is referred to as a fire cluster. Mean fire size for fire clusters was calculated as

Mean fire size $(\mathrm{MFS})_{i}=$ number of ASTER fire pixels ${ }_{i} /$ number of fire clusters $_{i}$, where $i$ is an index representing a given MODIS pixel. 
Earth Interactions - Volume 9 (2005) - Paper No. 9 - Page 12

\subsection{Logistic regression}

Similar to the work in southern Africa (Morisette et al. 2005), the comparison between MODIS and ASTER fire products is used to address the following three major questions.

1) What are the characteristics of fires that MODIS will almost always detect (probability of detection $\geq 0.95$ )?

2) What are the characteristics of fires that MODIS might detect (probability of detection $=0.50)$ ?

3) What are the characteristics of fires that MODIS will likely miss (probability of detection $<\leq .05)$ ?

We consider these three questions with respect to both the EOS and INPE algorithms.

To address these questions in a quantitative manner, we employed a logistic regression to relate the binary MODIS fire/no-fire product with summary statistics from the ASTER fire map. MODIS data were taken to be the response (or $y$ ) variable and the summary statistics derived from the ASTER data as the independent (or $x$ ) variable(s) within the context of logistic regression models. The model can be written as

$$
\pi\left(x_{i}\right)=\frac{e^{\beta_{0}+\sum_{j=1}^{p} \beta_{j} x_{i j}}}{1+e^{\beta_{0}+\sum_{j=1}^{p} \beta_{j} x_{i j}}},
$$

where $\sum_{j=1}^{p} \beta_{j} x_{i j}$ represents the linear combination of $p$ ASTER summary statistics within MODIS pixel $i, \pi\left(x_{i}\right)$ is the probability that MODIS pixel $i$ will be equal to 1 (i.e., labeled as fire) given the value of $x_{i}$, and the $\beta_{o}$ and $\beta_{j}$ parameters are estimated from the data (Agresti 1990).

The modeling was done with S-PLUS statistical software (Insightful Corporation, Seattle, Washington). The resulting models were then used to address the three questions regarding MODIS fire detection. We addressed the first question by evaluating the model at the $\pi\left(x_{i}\right)=0.95$ level, the second by considering $\pi\left(x_{i}\right)$ $=0.5$, and the third by evaluating the models at $\pi\left(x_{i}\right)=0.05$. While these particular values for $\pi\left(x_{i}\right)$ are somewhat arbitrary, the 0.05 and 0.95 values match probability levels that are typically associated with statistical testing, while values associated with the second question correspond to the midpoint where the probability of detection is as likely as nondetection. Actual models are given such that other values for $\pi\left(x_{i}\right)$ can be explored.

\subsection{Error matrices/accuracy assessment curves}

More so than logistic regression, typical remote sensing accuracy assessment is summarized through an error matrix. In the error matrix, the columns represent the reference data, while the rows represent the classified data (Aronoff 1982a,b). In 
Earth Interactions • Volume 9 (2005) • Paper No. 9 • Page 13

this context, the ASTER imagery is the reference data and the MODIS fire product is the classified data. However, for such an analysis the reference data should be collected at the same minimum mapping unit as the map that is being assessed (Congalton and Green 1999). The error matrix approach requires using the same classification scheme for both the reference data and classified map. These two issues imply the need to reduce the information from all ASTER pixels contained within one MODIS pixel to a simple binary classification of either fire or nonfire. That is, there is a need to convert the ASTER data to a $\sim 1 \mathrm{~km}$ binary fire product. This, in turn, requires developing a method for such a classification based on the summary statistics described above. Here we consider selecting a threshold for the number of ASTER fire counts beyond which we would classify the ASTER data within the MODIS pixel as fire. For example, a threshold of 10 would imply that when there are 10 or more ASTER fire pixels within the MODIS pixel, then the " $1 \mathrm{~km}$ " ASTER fire product would be classified as fire. Any count less then 10 would be classified as no fire.

Figure 2 illustrates how different ASTER fire count threshold values are related to the associated error matrix. The number of points falling in areas A, B, C, and $\mathrm{D}$ on the scatterplot shown in the upper portion of the figure are the values that fill the corresponding elements in the error matrix. Plotting error matrix values as a function of the classification threshold provides accuracy assessment curves (Morisette and Khorram 2000) from which we can compare the EOS and INPE algorithms.

\section{A given threshold...}

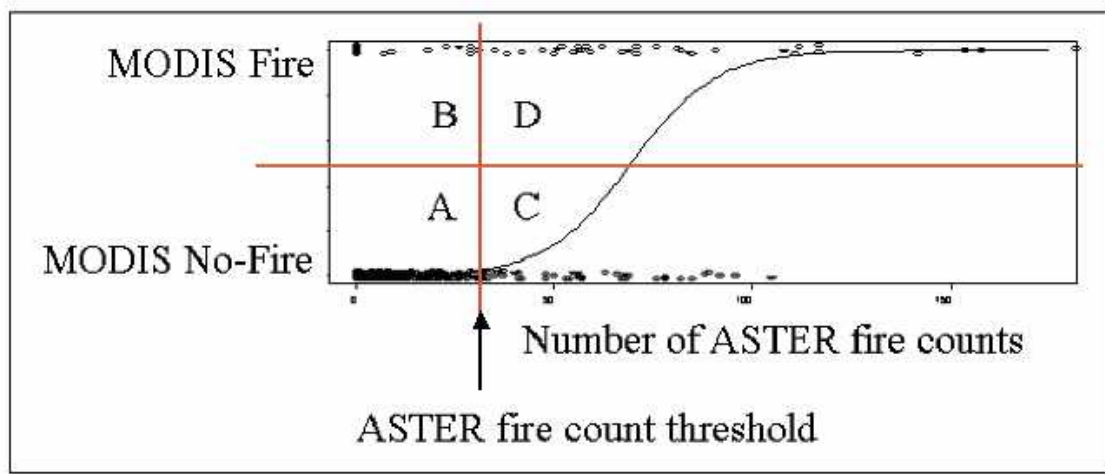

...will result in a specific error matrix.

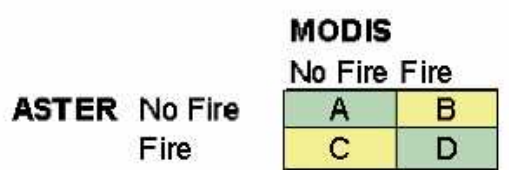

Figure 2. Diagram illustrating the creation of an error matrix for a given ASTER fire count threshold used to classify the 1-km ASTER data as fire. 
Earth Interactions - Volume 9 (2005) - Paper No. 9 • Page 14

\section{Results}

\subsection{ASTER summaries}

The number of ASTER fire pixels labeled as fire for all 22 scenes was 12439 . These pixel counts came from 982 contiguous fire clusters. Figure 3 through Figure 6 provide examples of data from which all of the results are derived and provide a visual demonstration of the difference in scale between the MODIS and
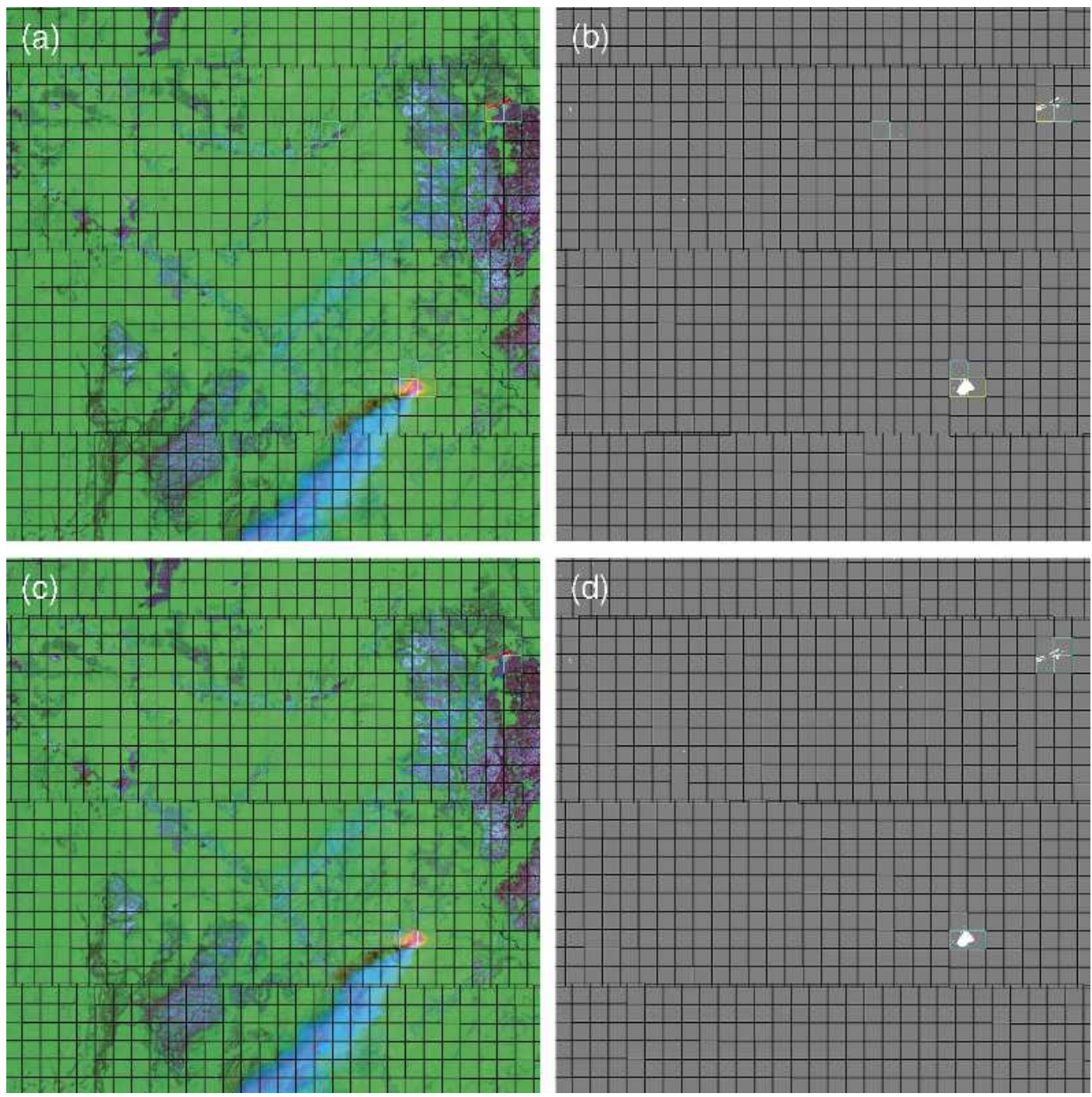

Figure 3. MODIS 1-km grids and fire detections over ASTER imagery and binary ASTER fire masks on 28 Jan 2003 in Roraima: (a) EOS fire detection, ASTER 8-3-1 RGB image; (b) EOS fire detection, ASTER binary fire map; (c) INPE fire detection, ASTER 8-3-1 RGB image; (d) INPE fire detection, ASTER binary fire mask. MODIS EOS fire detection is shown as yellow and blue grid cells for high and nominal confidence, respectively. 
Earth Interactions - Volume 9 (2005) • Paper No. 9 • Page 15
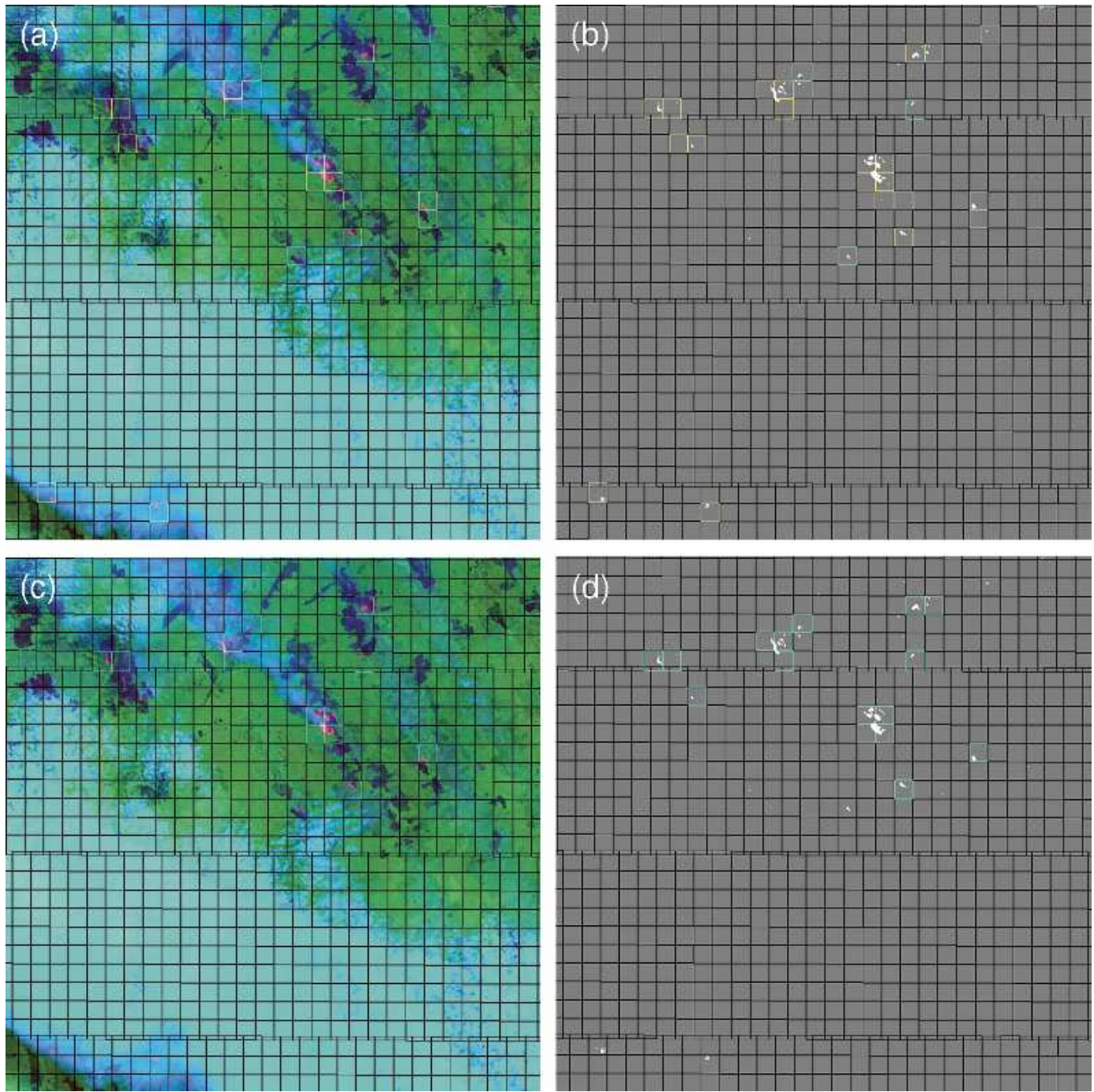

Figure 4. Same as Figure 3, but on 29 Aug 2003 in Acre.

ASTER data. The figures show the MODIS 1-km grids over the ASTER imagery and over the corresponding binary ASTER fire maps. The MODIS grid is color coded to indicate MODIS fire detections from the EOS and INPE algorithms. The yellow and blue boxes on the MODIS EOS grid indicate fire pixels with "high" and "nominal" confidence, respectively. Because the MODIS INPE algorithm does not provide confidence levels, all of the MODIS fire pixels are blue in color on the MODIS INPE grid. The colors of the ASTER band 8-3-1 red-green-blue (RGB) imagery are stretched to show fires in red. A comparison of the ASTER imagery with the corresponding binary ASTER fire masks shows that the ASTER fire detection algorithm works well. Each ASTER scene's fire mask used in this study was visually inspected against the corresponding, linked image of the original ASTER imagery at full resolution. This visual inspection found no falsely 
Earth Interactions - Volume 9 (2005) • Paper No. 9 • Page 16
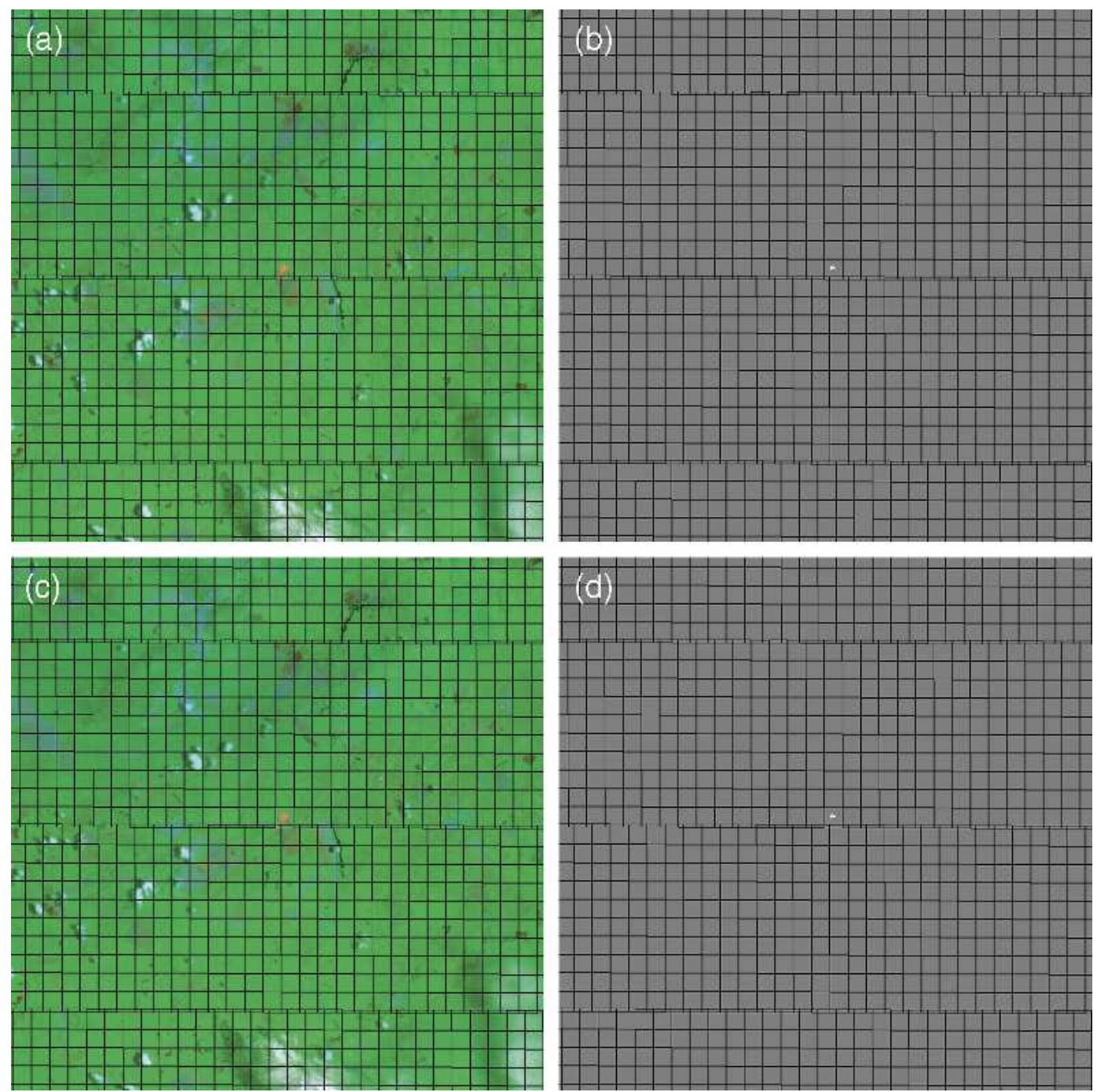

Figure 5. Same as Figure 3, but on 8 Oct 2003 in Tapajós.

detected or missed fires. The last column in Table 1 notes which ASTER scenes are represented in the figures presented here.

The 28 January 2003 images (Figure 3) are from Roraima. The large fire near the lower-right corner is a prescribed burn set by the LBA-Ecology (ECO) LC-23 project team, which was also observed from aircraft and on the ground. The INPE algorithm flagged the two MODIS pixels that included most of the fire front. The EOS algorithm also flagged a third pixel at nominal confidence level, which covers the edge of the fire front. There is an additional fire $\sim 15 \mathrm{~km}$ to the north. A larger fire front is visible at the edge of a large burn scar. Here the INPE algorithm correctly flagged all three MODIS pixels with a significant amount of fire. The EOS algorithm, however, missed one pixel here. On the EOS MODIS grid there are also two pixels flagged at nominal confidence $\sim 8 \mathrm{~km}$ to the west of this fire front. These pixels include rather small fires and remain undetected by the INPE 
Earth Interactions • Volume 9 (2005) • Paper No. 9 • Page 17
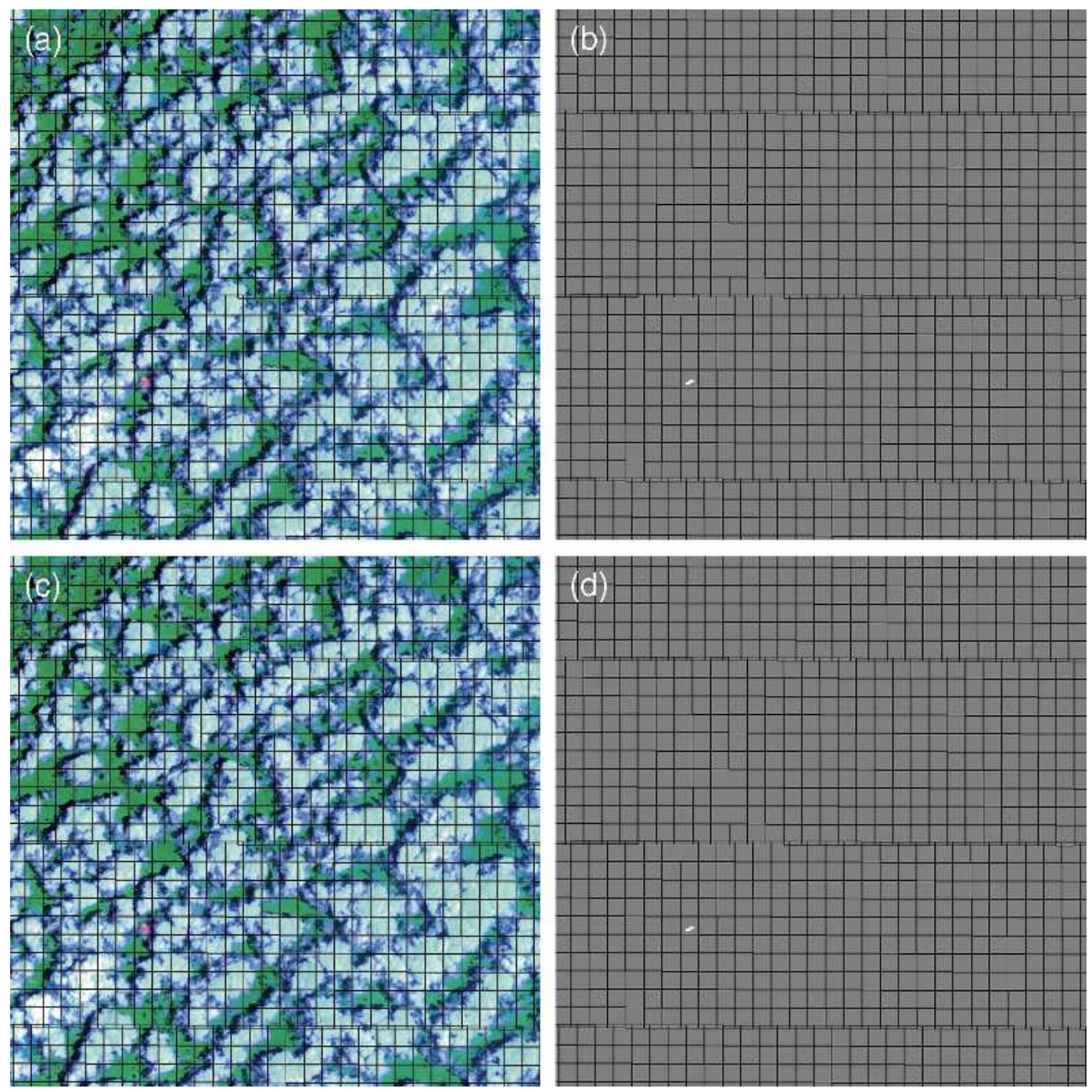

Figure 6. Same as Figure 3, but on 24 Oct 2003 in Tapajós.

algorithm. Both algorithms also missed several small fires seen in the western half of the scene.

The 29 August 2003 image (Figure 4) is from Acre, an area that includes many fires and has been studied extensively by the LBA-ECO Land Cover and Land Use Change-02 team, with whom the authors have been collaborating. The comparison of the EOS and INPE MODIS fire products shows that, in general, the EOS algorithm detects more of the smaller fires. For example, obvious fires beneath thin cloud edges near the lower-left corner of the scene are detected by the EOS algorithm, but are missed by the INPE algorithm. On the other hand, the EOS algorithm also produced a few apparently false detections (i.e., no ASTER fire pixels).

The ASTER scene from 8 October 2003 in Tapajós (Figure 5) includes only one larger fire near the center. This fire was detected by the INPE algorithm, but 
Earth Interactions • Volume 9 (2005) • Paper No. 9 • Page 18

missed by the EOS algorithm. Another scene from Tapajós on 24 October 2003 (Figure 6) shows a fire among clouds in the lower-left part of the image. This is a prescribed fire set by the LBA LC-23 team. Both the INPE and the EOS algorithms, probably because of cloud contamination, missed this rather large fire. We now proceed to a more quantitative assessment.

\subsection{Logistic regression}

The logistic modeling indicates that both the ASTER fire counts and MFS, as well as the cross product (or interaction) between them, are all significant variables for the model applied to the MODIS EOS observations ( $p$ values $<0.001$ ), and that the ASTER fire counts as well as the interaction between the counts and MFS are significant variables for the MODIS INPE algorithm. For consistency, while not a highly significant variable for the INPE model, the MFS variable is included in both models. That is, to address the three questions related to probability of detection, we use the model

$$
\pi\left(x_{i}\right)=\frac{e^{\beta_{0}+\beta_{1} \text { Counts }_{i}+\beta_{2} \mathrm{MFS}_{i}+\beta_{3} \text { Counts }_{i} \times \mathrm{MFS}_{i}}}{1+e^{\beta_{0}+\beta_{1} \operatorname{Counts}_{i}+\beta_{2} \mathrm{MFS}_{i}+\beta_{3} \operatorname{Counts}_{i} \times \mathrm{MFS}_{i}} .}
$$

The estimated parameter values and their $p$ values are given in Table 2. The higher the absolute value of the parameter, the more sensitive that response variable is to the associated variable. So, while the parameters for the INPE and EOS algorithms are similar, we see that the EOS algorithm shows slightly more sensitivity to the ASTER fire counts and much more sensitivity to MFS. The resulting model surface and the data combined for all 22 scenes are shown in Figure 7. Decreasing probabilities for high counts and large MFS values (seen in the upper right for Figures $7 \mathrm{a}$ and $7 \mathrm{~b}$ ) are the result of the negative coefficient on the cross-product terms and applying the model beyond the range of data. This can be addressed by adjusting the model to

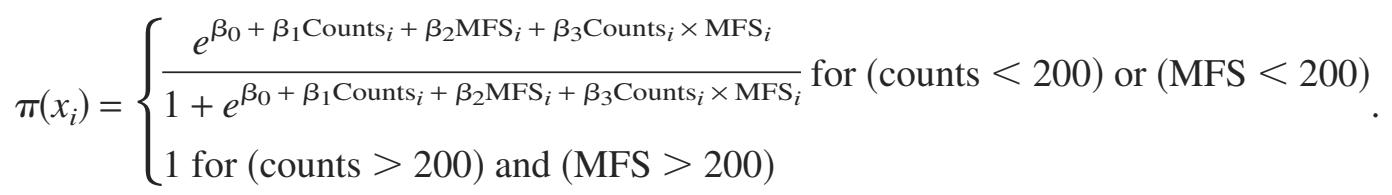

Using this model, we can address the question related to detection probabilities. This is done by plotting the contour lines for the $0.05,0.50$, and 0.95 probability levels on the modeled surface. These contour lines are shown in Figure 8.

Table 2. Logistic regression parameters, standard errors, and $p$ values. (The $p$ values are calculated by adding terms sequentially (first to last), based on an S-PLUS ANOVA chi-square probability.)

\begin{tabular}{crlcccr}
\hline Parameter & \multicolumn{1}{c}{ EOS } & Std error & $p$ value & INPE & Std error & $p$ value \\
\hline$\beta_{0}$ & -7.5989 & 0.154 & & -6.50 & 0.0893 & \\
$\beta_{1}$ & 0.0947 & 0.0072 & $<.0001$ & 0.0854 & 0.0075 & $<0.0001$ \\
$\beta_{2}$ & 0.0956 & 0.0140 & 0.0003 & 0.0524 & 0.0184 & 0.1932 \\
$\beta_{3}$ & -0.0006 & 0.00004 & $<.0001$ & -0.0004 & 0.00008 & 0.0065 \\
\hline
\end{tabular}


(a) Estimated INPE Algorithm Detection Probabilities

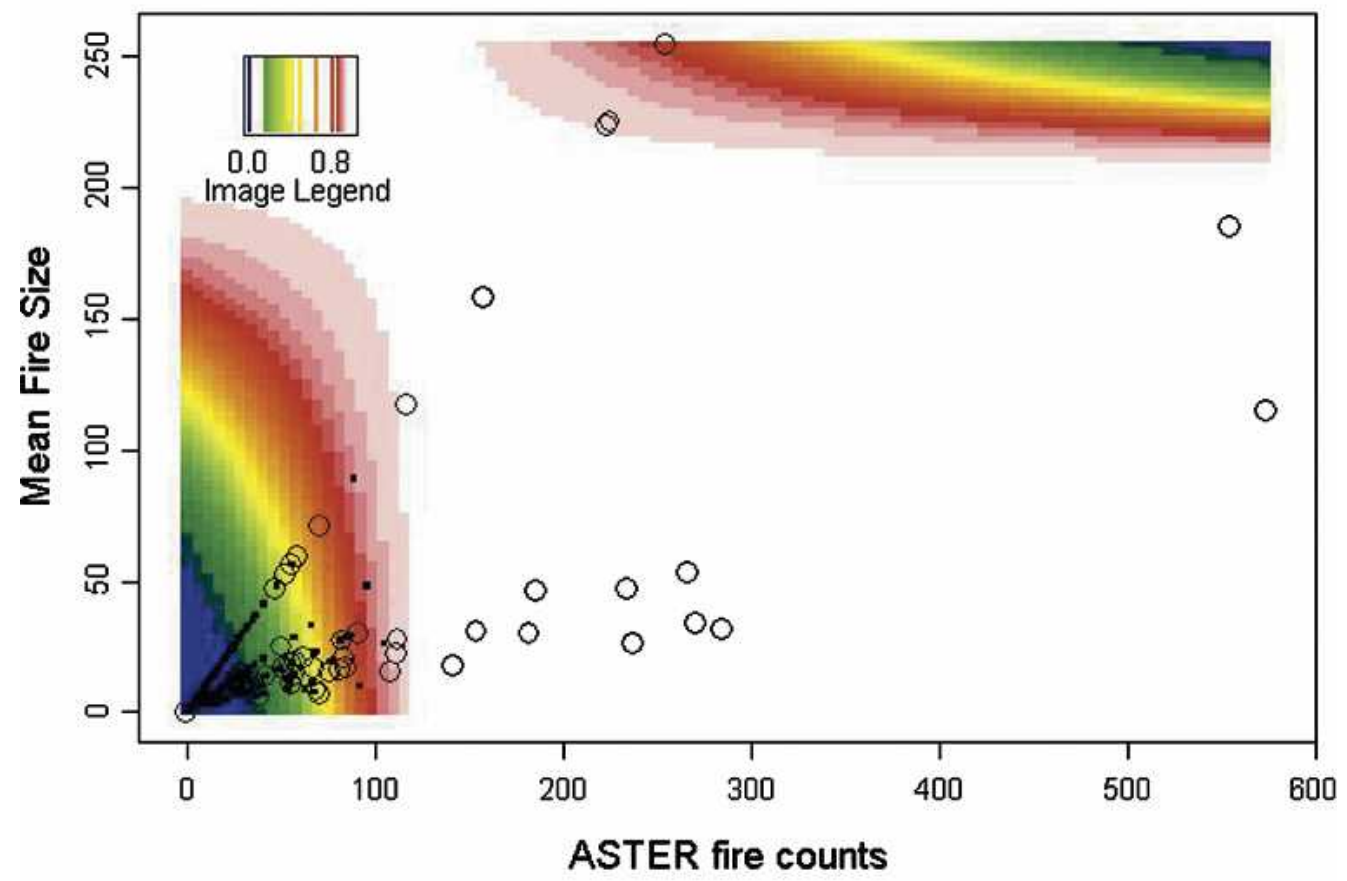

(b) Estimated EOS Algorithm Detection Probabilities

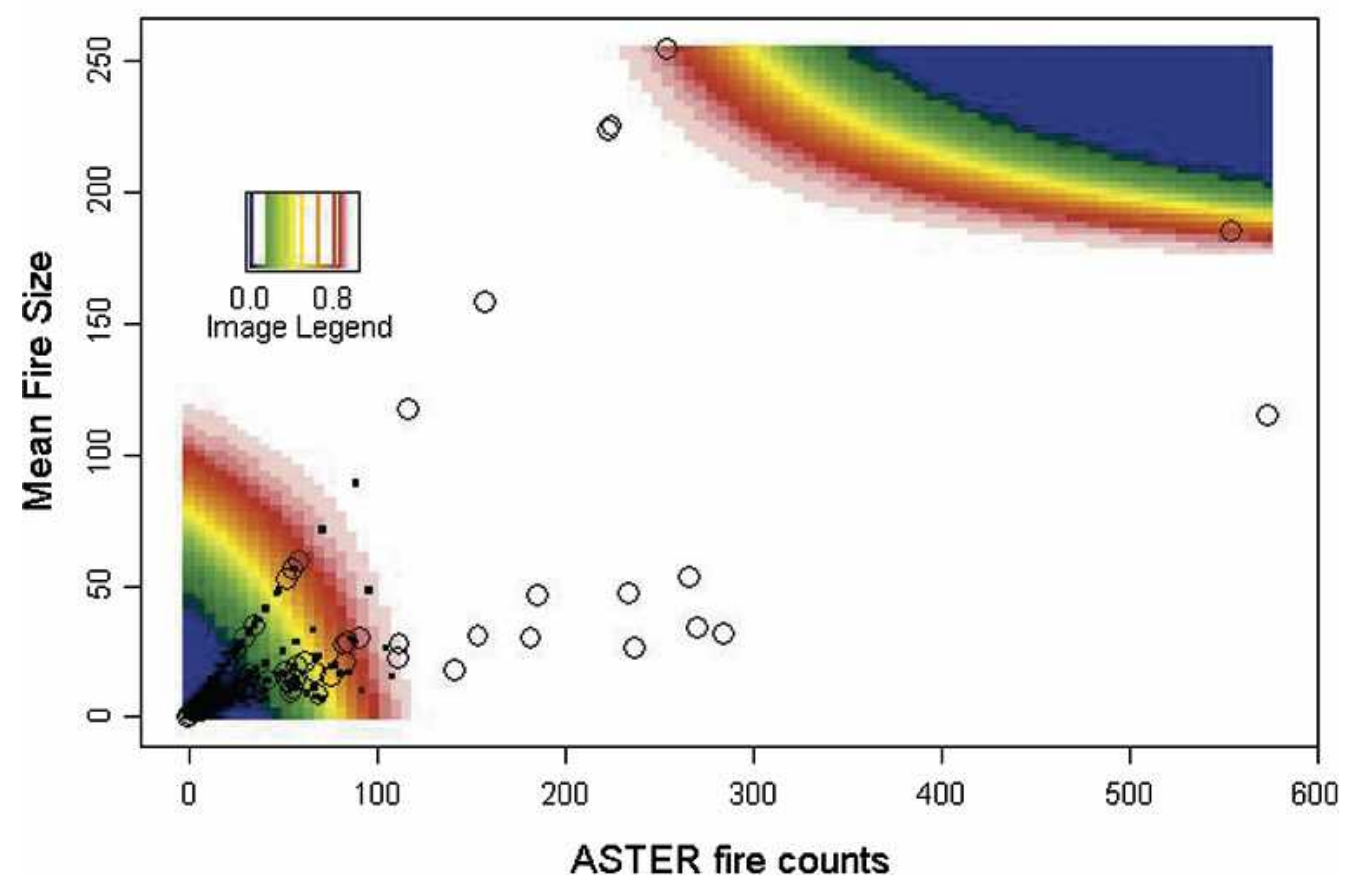

Figure 7. Modeled probability surface and observed data. The open circles indicate MODIS fire detections and smaller closed squares are pixels without a MODIS fire detection; the (a) INPE and (b) EOS algorithm. 


\section{Contour Plot of Detection Probabilities}

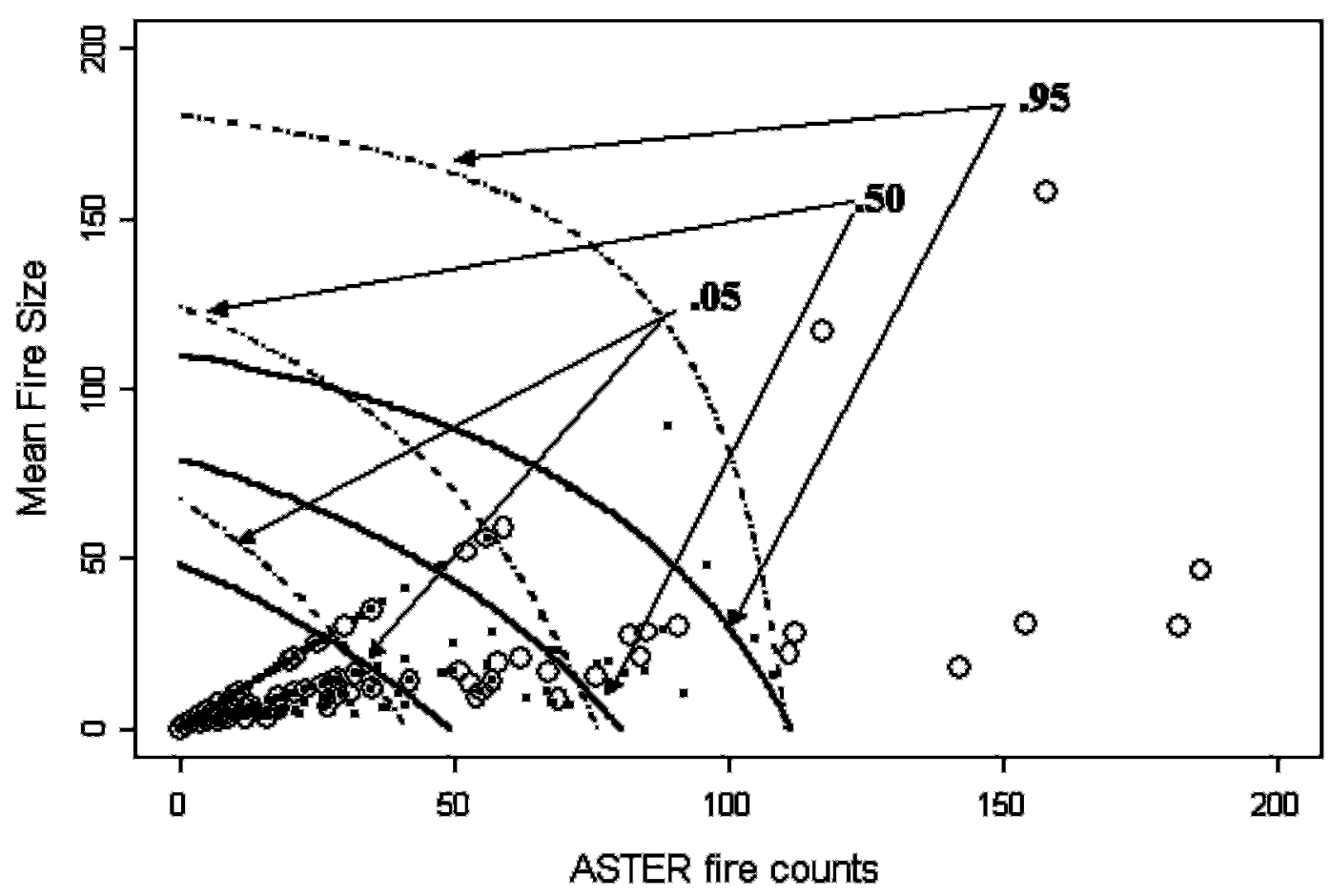

Figure 8. Contour lines for the $0.05,0.50$, and 0.95 probability levels for the logistic regression model for the EOS and INPE algorithm. The solid line represents the model derived from the EOS algorithm, and the dashed line represents the model derived from the INPE algorithm.

\subsection{Accuracy assessment curves}

To help explain the accuracy assessment curve concept, we first present three error matrices and related accuracy figures for three different ASTER fire count thresholds for the INPE data. Figure 9 shows the three error matrices and related error probabilities (following the diagram in Figure 2). When we classify the ASTER data as a fire for even one ASTER fire count, then the probability of the INPE algorithm missing a fire (omission error) is rather high, at 0.8671 . However, we see that the chance of this error decreases significantly as we require more ASTER fire counts before we classify the area as fire. When we require 50 ASTER fire counts before we classify the area as fire, the probability of the INPE algorithm missing a fire is 0.375 . When we require 100 ASTER fire counts before we classify the area as fire, the probability of the INPE algorithm missing a fire is 0.045 . So, the probability of an error behaves as expected. That is, a bigger fire based on the number of ASTER fire counts is more likely to be detected by the INPE algorithm. A plot of the omission error as a function of the ASTER fire detection threshold is given in Figure 10. On this figure the three vertical red lines are the threshold values shown in Figure 9. It is interesting to see how close the 


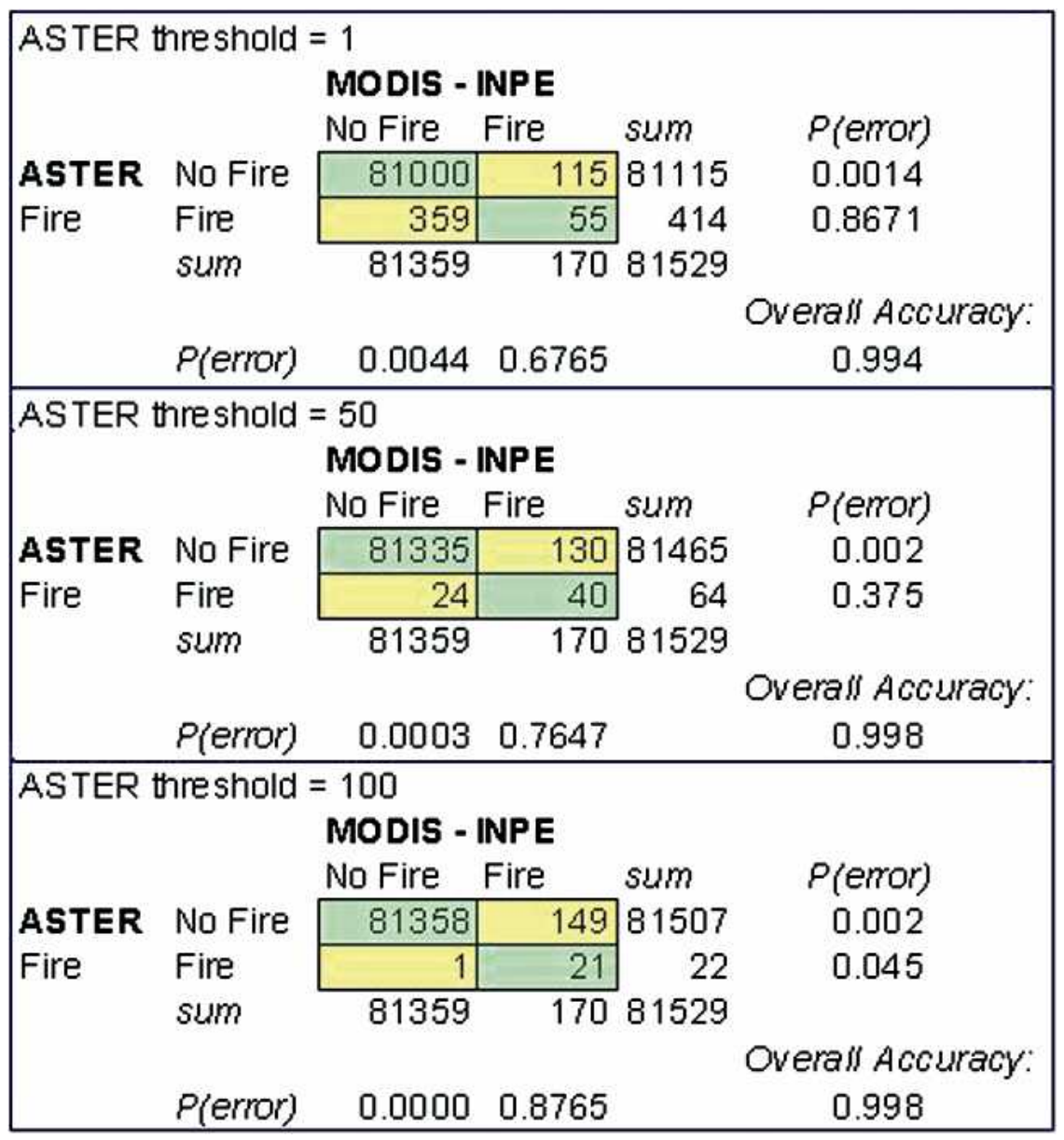

Figure 9. Three-error matrix for three different ASTER count threshold values applied to the INPE algorithm.

omission errors are from the INPE and EOS algorithms. While there is general agreement, it is shown that for small fires (threshold values less than 20 ASTER fire counts) the EOS algorithm is better (lower probability for omission error), but for larger fires (counts greater than 20) the INPE algorithm has lower omission error probabilities.

Consider now the probability of MODIS detecting a fire when the ASTER 1-km classification indicates that there is no fire (commission errors). Here, increasing the threshold penalized the MODIS algorithm because very small fires can be detected by the INPE algorithm yet fall below the ASTER fire count threshold and so are put in the ASTER data's no-fire column in the error matrix. For the three error matrices in Figure 9 we see that the commission error increases from 0.0014 to 0.002 as the thresholds increases from 1 to 50 . The probability of commission error remains 0.002 for the threshold of 100 . The downside to the analysis is that the MODIS detection of a small fire below the threshold is not really an error. So, perhaps the most useful values to consider for commission error are the commission error probabilities for the threshold of 1 . Figure 11 shows the probability of 


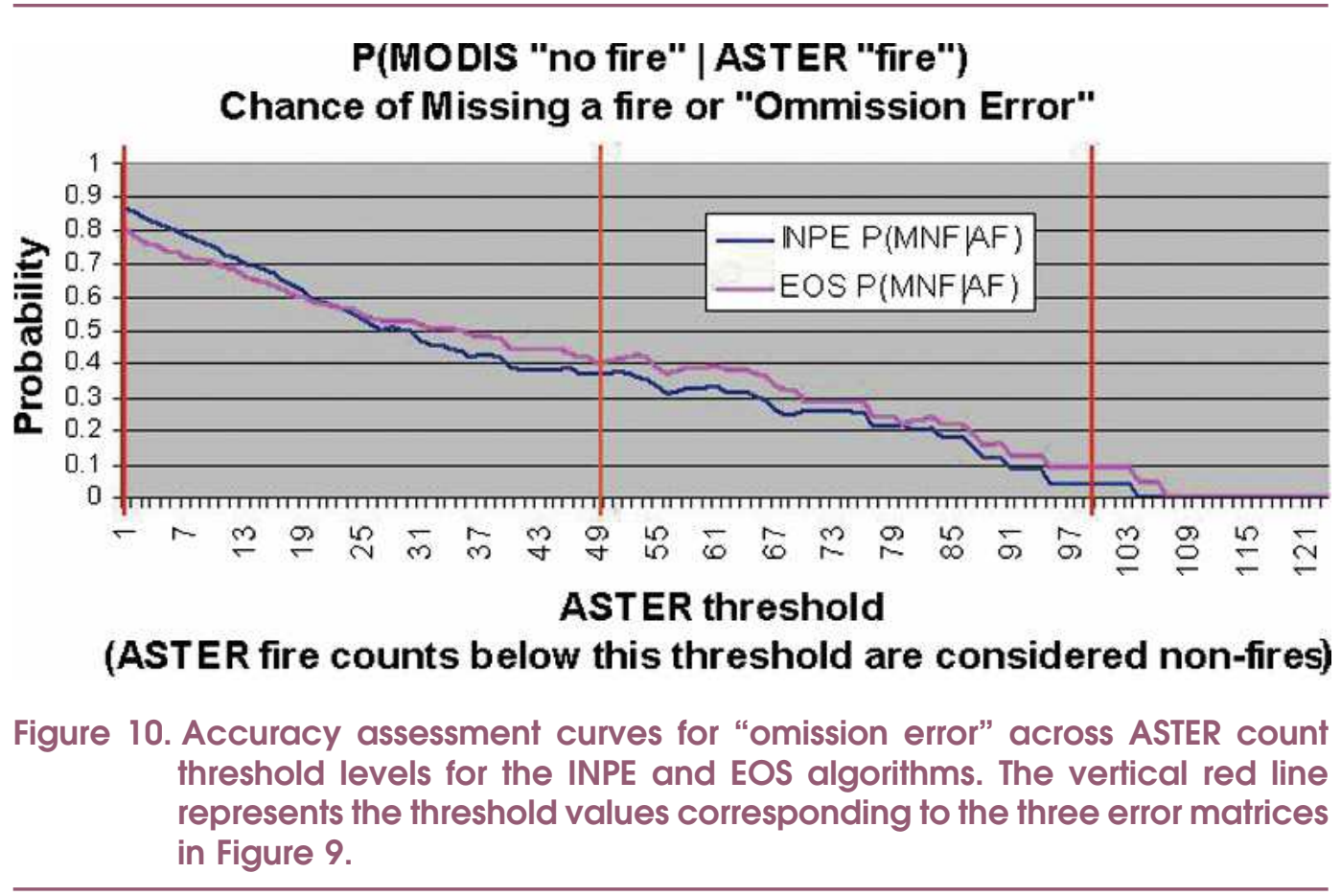

commission errors as a function of ASTER fire threshold, and again the red vertical bars correspond to the threshold values corresponding to the error matrices in Figure 9. But, again, the most useful threshold value to consider is the threshold value of 1 . Here we see an order of magnitude difference between the EOS and

\section{P(MODIS "fire" | ASTER "no fire") = False positive or "commission error"}

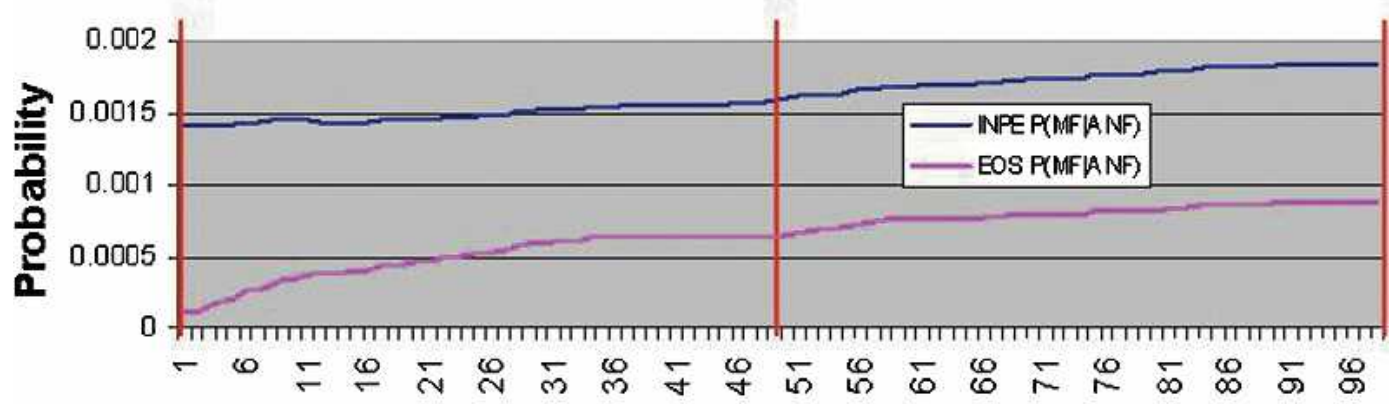

\section{ASTER threshold}

(ASTER fire counts below this threshold are considered non-fires)

Figure 11. Accuracy assessment curves for "commission error" across ASTER count threshold levels for the INPE and EOS algorithms. The vertical red line represents the threshold values corresponding to the three error matrices in Figure 9. 
Earth Interactions • Volume 9 (2005) - Paper No. 9 • Page 23

INPE algorithm. The probability of commission error for the EOS algorithm is 0.0001 , while for the INPE algorithm it is 0.0014 . Both values are extremely low because of the large number of cases where both MODIS and ASTER classify the area as no fire.

\section{Conclusions and discussion}

The primary conclusion is that both algorithms do a fairly good job detecting fires, as compared to the fire detection from ASTER imagery. It is encouraging to see that the results from the error matrix analysis are similar to those of the logistic regression modeling. The algorithms show similarities in the detection probabilities from the logistic regression and in the probability of omission error from the error matrix approach. However, the EOS product shows much lower commission error probabilities.

It is worth noting that by comparing to ASTER data, we are only considering fires within the look-angle range of ASTER's SWIR bands: $\pm 8.55^{\circ}$. There is also a chance that clouds can obscure fire detection from both ASTER and MODIS fire detection algorithms. However, any bias as a result of look-angle cloud cover should be consistent between the INPE and EOS ASTER comparison. So, the comparison presented here is legitimate despite the caveats. It is also worth noting that the issues of cloud cover and look angle will increase the likelihood that the MODIS algorithm misses a fire (Schroeder et al. 2005). With this, the MODIS fire detection from either algorithm can be thought of as a lower bound for the true number of fires. Within $\pm 8.55^{\circ}$, the accuracy of the fire detection for either algorithm is relayed through Figure 8. For MODIS imagery, with a look angle beyond $\pm 15^{\circ}$, the chance of missing a fire is likely higher than the values presented here and will increase as a function of the look angle.

Future efforts are being directed to more fully exploit the radiative information contained in the ASTER data. For example, the cumulative radiance from the ASTER fire detections could be added as a parameter in the logistic regression modeling used to determine MODIS fire detection limits. The cumulative radiance may explain some of the errors of omission.

It is important to realize the difference between the EOS and INPE algorithms. The EOS product is meant for both wildfire management and global climate modeling. The product will be archived and it is meant to serve as a long-term climate data record. The INPE product is primarily produced for fire management purposes. It is a straightforward algorithm that is run on the digital numbers from the MODIS direct broadcast. Indeed, we see from this analysis here that INPE's relatively straightforward, near-real-time algorithm is very similar to the EOS algorithm with respect to omission error, and the INPE algorithm is even superior for larger fires. While the chance of a commission error is very small for both algorithms (primarily because of the large number of nonfires), the EOS algorithm is superior. However, the objective for this paper is not to say which algorithm is better, but rather to simply assess the uncertainty of each through independently derived fire products. It is left to users and further research to build upon the analysis presented here to determine the best use of products from either algorithm or both. 
Earth Interactions • Volume 9 (2005) • Paper No. 9 • Page 24

Acknowledgments. This work is funded under the LBA-Ecology program, with thanks to its program manager, Diane Wickland, and project manager, Darrel Williams, for their support. Thanks also to two anonymous reviewers who provided helpful comments.

\section{References}

Agresti, A., 1990: Categorical Data Analysis. John Wiley and Sons, 558 pp.

Andreae, M. O., and Coauthors, 1988: Biomass burning emissions and associated haze layers over Amazonia. J. Geophys. Res., 93 (D2), 1509-1527.

Aronoff, S., 1982a: Classfication accuracy: A user approach. Photogramm. Eng. Remote Sens., 48, 1299-1307.

—_, 1982b: The map accuracy report: A user's view. Photogramm. Eng. Remote Sens., 48, $1309-1312$.

Congalton, R. G., and K. Green, 1999: Assessing the Accuracy of Remotely Sensed Data: Principles and Practices. Lewis Publishers, 137 pp.

Dozier, J., 1981: A method for satellite identification of surface temperature fields of subpixel resolution. Remote Sens. Environ., 11, 221-229.

Dwyer, E., S. Pinnock, J.-M. Grégoire, and J. M. C. Pereira, 2000: Global spatial and temporal distribution of vegetation fire as determined from satellite observations. Int. J. Remote Sens., 21, 1289-1302.

Elvidge, C. D., V. R. Hobson, K. E. Baugh, J. B. Dietz, Y. E. Shimabukuro, T. Krug, and E. M. L. M. Novo, 2001: DMSP-OLS estimation of tropical forest area impacted by surface fires in Roraima, Brazil: 1995 versus 1998. Int. J. Remote Sens., 22, 2661-2673.

Eva, H., and E. F. Lambin, 2000: Fires and land-cover change in the tropics: A remote sensing analysis at the landscape scale. J. Biogeogr., 27, 765-776.

França, H., and A. Setzer, 2001: AVHRR analysis of a Savanna site through a fire season in Brazil. Int. J. Remote Sens., 22, 2449-2461.

Giglio, L., J. Descloitres, C. O. Justice, and Y. Kaufman, 2003: An enhanced contextual fire detection algorithm for MODIS. Remote Sens. Environ., 87, 273-282.

Goldammer, J. G., 1990: Fire the Tropical Biota. Springer-Verlag, 497 pp.

Justice, C. O., and P. Dowty, 1994: The IGBP Satellite fire detection algorithm workshop technical report. IGBP-DIS, Paris, France, 88 pp.

— , and Coauthors, 2002: The MODIS fire products. Remote Sens. Environ., 83, 244-262.

Kaufman, Y. J., and Coauthors, 1998: Potential global fire monitoring from EOS-MODIS. $J$. Geophys. Res., 103, 32 215-32 238.

Li, Z., Y. Kaufman, C. Ichoku, R. Fraser, A. Trishchenko, L. Giglio, J.-Z. Jin, and X. Yu, 2001: A review of AVHRR-based fire detection algorithms: Principles, Limitations and Recommendations. Global and Regional Wildfire Monitoring from Space: Planning a Coordinated International Effort, F. Ahern, J. Goldammer, and C. O. Juctice, Eds., SPB Academic Publishing, 199-225.

Malingreau, J. P., and J. M. Gregoire, 1996: Developing a global vegetation fire monitoring system for global change studies: A framework. Remote Sensing and Modeling of Biomass Burning, and Biomass Burning in the Boreal Forest, J. S. Levine, Ed., Biomass Burning and Global Change, Vol. 1, The MIT Press, 14-23.

Matson, M., and J. Dozier, 1981: Identification of subresolution high temperature sources using a thermal IR sensor. Photogramm. Eng. Remote Sens., 47, 1311-1318.

Molenar, D. A., K. J. Schrab, J. F. W. Purdom, and H. Gosden, 1996: RAMSDIS in digital satellite data training and analysis. Preprints, 12th Int. Conf. on Interactive Information and Processing Systems (IIPS) for Meteorology, Oceanography and Hydrology, Atlanta, GA, Amer. Meteor. Soc., 160-163. 
Morisette, J. T., and S. Khorram, 2000: Accuracy assessment curves for satellite-based change detection. Photogramm. Eng. Remote Sens., 66, 876-880.

— J. L. Privette, and C. O. Justice, 2002: A framework for the validation of MODIS land products. Remote Sens. Environ., 83, 77-96.

— L.Giglio, I. Csiszar, and C.O. Justice, 2005: Validation of the MODIS active fire product over Southern Africa with ASTER data. Int. J. Remote Sens., in press.

Pereira, J. M. C., and Coauthors, 2002: Operational use of remote sensing for fire management: Regional case studies. Global and Regional Vegetation Fire Monitoring from Space: Planning a Coordinated International Effort, F. J. Ahern, J. G. Goldammer, and C. O. Justice, Eds., Kugler, 303 pp.

Potter, C., V. B. Genovese, S. Klooster, M. Bobo, and A. Torregrosa, 2001: Biomass burning losses of carbon estimated from ecosystem modeling and satellite data analysis for the Brazilian Amazon region. Atmos. Environ., 35, 1773-1781.

Prins, E. M., J. M. Feltz, W. P. Menzel, and D. E. Ward, 1998: An overview of GOES-8 diurnal fire and smoke results for SCAR-B and 1995 fire season in South America. J. Geophys. Res., 103 (D24), 31 821-31 835.

Schroeder, W., J. Morisette, I. Csiszar, L. Giglio, D. Morton, and C. Justice, 2005: Characterizing vegetation fire dynamics in Brazil through multi-satellite data: Common trends and practical issues. Earth Interactions, submitted.

Setzer, A. W., and M. Pereira, 1991a: Operational detection of fires in Brazil with NOAA-AVHRR. Proc. 24th. Int. Symp. on Remote Sensing of the Environment, Rio de Janeiro, Brazil, Environmental Research Institute of Michigan (ERIM), 469-482.

, and - 1991b: Amazonia biomass burnings in 1987 and an estimate of their tropospheric emissions. Ambio, 20 (1), 19-22.

_ , and J. P. Malingreau, 1996: AVHRR monitoring of vegetation fires in the Tropics: Toward the development of a global product. Biomass Burning and Global Change, Vol. 1, Remote Sensing and Modeling of Biomass Burning, and Biomass Burning in the Boreal Forest, J. S. Levine, Ed., MIT Press, 632 pp.

— A. C. Pereira Jr., and M. C. Pereira, 1994: Satellite studies of biomass burning in Amazonia: Some practical aspects. Remote Sens. Rev., 10, 91-103.

USCCSP, 2004: Our Changing Planet, The U.S. Climate Change Science Program for Fiscal Years 2004 and 2005. A Report by the Climate Change Science Program and Subcommittee on Global Change Research. A Supplement to the President's Fiscal Year 2004 and 2005 Budgets (see http://www.usgcrp.gov/usgcrp/Library/ocp2004-5/default/htm).

Yamaguchi, Y., A. B. Kahle, H. Tsu, T. Kawakami, and M. Pniel, 1998: Overview of Advanced Spaceborne Thermal Emission and Reflection Radiometer (ASTER). IEEE Trans. Geosci. Remote Sens., 36, 1062-1071.

Earth Interactions is published jointly by the American Meteorological Society, the American Geophysical Union, and the Association of American Geographers. Permission to use figures, tables, and brief excerpts from this journal in scientific and educational works is hereby granted provided that the source is acknowledged. Any use of material in this journal that is determined to be "fair use" under Section 107 or that satisfies the conditions specified in Section 108 of the U.S. Copyright Law (17 USC, as revised by P.IL. 94-553) does not require the publishers' permission. For permission for any other form of copying, contact one of the copublishing societies. 